\title{
Atuação e práticas na Psicologia Escolar no Brasil: revisão sistemática em periódicos
}

\author{
Graciele Malheiro dos Santos'; http://orcid.org/0000-0001-6647-5496 \\ Leonídia Aparecida Pereira da Silva ${ }^{1}$; https://orcid.org/0000-0002-0382-3315 \\ Josenith Lima Pereira1; https://orcid.org/0000-0001-8806-2828 \\ Ângelo Giuseppe Xavier Lima1; https://orcid.org/0000-0003-1572-5699 \\ Francisco Leandro de Assis Neto'; https://orcid.org/0000-0002-4319-8446
}

\begin{abstract}
Resumo
O presente artigo tem como objetivos analisar como se dão a atuação e as práticas desenvolvidas por psicólogo(s)/a(s) na área de escolar e educacional, bem como realizar uma revisão sistemática no período de janeiro de 2000 a setembro de 2017, por meio de bases de indexação de acesso livre. Seis artigos foram incluídos e outros 168 excluídos após análise. Foram identificadas ações em: a) Escolas de nível infantil, fundamental e médio; b) Ensino superior; c) Organizações não-governamentais, com foco nas ações para o desenvolvimento e a aprendizagem dos alunos. Houve dificuldades acerca da pouca produção na área, condições e processos de trabalho, fragilidade da área nos espaços institucionais e resistência a superação de práticas individuais. As possibilidades ocorreram a partir das práticas associativas, democráticas e coerentes no cenário de inserção do profissional.
\end{abstract}

Palavras-chave: Psicologia Escolar; atuação do psicólogo; revisão de literatura.

\section{Performance and practices in school psychology in Brazil: systematic review in periodicals}

\begin{abstract}
The present article aims to analyze how the performance and practices developed by psychologist (s) in the school and educational area are performed, as well as to carry out a systematic review in the period from January 2000 to September 2017, for access databases. Six articles were included and 168 others excluded after analysis. Actions have identified in: a) Primary and secondary schools; b) Higher education; c) Nongovernmental organizations, focusing on actions for the development and learning of students. The difficulties have related to the low production in the area, conditions and work processes, fragility of the area in the institutional spaces and resistance to overcoming individual practices. The possibilities were based on associative, democratic and coherent practices in the professional insertion scenario.
\end{abstract}

Keywords: School Psychology; psychologist performance; literature review.

\section{Actuación y prácticas en la psicología escolar en Brasil: revisión sistemática en periódicos}

\section{Resumen}

Analizar cómo ocurren la actuación y las prácticas desarrolladas por psicólogo(s)/a(s) en el área escolar y educacional. Revisión sistemática en el período de enero de 2000 a septiembre de 2017, por intermedio de bases de indexación de acceso libre. Seis artículos fueron incluidos y otros 168 excluidos tras análisis. Fueron identificadas acciones en: a) Escuelas de nivel infantil, primaria y secundaria; b) Enseñanza universitaria; c) Organizaciones nogubernamentales, con enfoque en las acciones para el desarrollo y el aprendizaje delos alumnos. Hubo dificultades acerca de la poca producción en el área, condiciones y procesos de trabajo, fragilidad del área en los espacios institucionales y resistencia a la superación de prácticas individuales. Las posibilidades sucedieron a partir de las prácticas asociativas, democráticas y coherentes en elescenario de inserción do profesional.

Palabras clave: Psicología Escolar; actuación del psicólogo; revisión de literatura.

1 Universidade Federal de Campina Grande - Campina Grande - PB - Brasil; malheiropsi@gmail.com;leonidiapereira1@gmail.com; prajosenith@hotmail.com; angeloxavier@uol.com.br;leandroassis.uepb@gmail.com 


\section{Introdução}

A Psicologia Escolar e Educacional (PEE) é uma importante área de atuação da Psicologia no país, possuindo uma longa história na constituição das instituições educativas do Estado brasileiro. Trajetória essa que não se abstémdas dificuldades e dos conflitos teóricos e práticos entre os entes envolvidos (Barbosa, 2011). A interface da psicologia e da educação é um encontro beligerante, e a essa característica acrescentam-se as diferentes perspectivas das instituições de ensino e as múltiplas bases teóricas,as quais a formação permite ao psicólogo (Coll, 2004). Mesmo que algumas ênfases destaquem-se sendo as mais utilizadas, como a histórico-cultural e a cognitiva no ensino superior e fundamental (Guzzo, Mezzalira, Moreira, Tizzei, \& Silva-Neto, 2010), cada profissional baliza sua atuação pela fundamentação teórica de sua preferência.

A celeuma no espaço escolar é de cunho epistêmico, ideológico, político e prático. Assim, a psicologia como mais um agente deste espaço, apresenta-se, ainda, sob muitas expectativas de suas ações (Moreira \& Guzzo, 2014). No entanto, decide-se aqui de forma teórica, por corroborar que ao profissional cabe uma leitura crítica e compromissada de sua atuação/formação, para por meio desta, refletir os contextos sociais/culturais/históricos dos espaços educacionais, com vistas ao desenvolvimento de processos educativoscriativos e de qualidade para a efetivação do desenvolvimento dos estudantes (Martinez, 2010). Desta forma, enfrenta-sea lógica da produção de dificuldades do processo de ensino-aprendizagem balizadas por epistemes biomédicas e por intervenções psicológicas que se destinam ao controle das queixas escolares com atendimentos clínicos e avaliações psicométricas (Machado, 2003). Por conseguinte, enxerga-se a escolacomo o principal agente de inserção social; o desenvolvimento de articulação da família e escola; a inclusão de professores nas atividades multiprofissionais; as compreensões de como os contextos produzem e manifestam os conflitos individuais, dentre outros (Souza \& cols., 2014). Acredita-se que com relação às questões de formação e de atuação possa haver o enfrentamento, na PEE, do movimento da lógica de individualizar e culpar os discentes exclusivamente pelos seus fracassos escolares, desresponsabilizando assim, o produtor real das desigualdades sociais, que é o sistema político e social (Machado, 2003), além do econômico.

Dessa forma, cabe destacar como a dinâmica escolar exige uma permanente avaliação e adequação não só das atividades educacionais, como da/para a PEE, afinal, o cenário per si é contextual e relacional, tornando-se passível de infinitas possibilidades para a ação do desenvolvimento humano. O psicólogo escolar e educacional precisa superar a cristalização do seu espaço de atuação profissional, vislumbrando não apenas os processos educativos de ensino e aprendizagem e/ou as queixas escolares, pois ela acaba por endossar a "adaptação" dos alunos (Pasqualini, Souza, \& Lima, 2013). O desafio atual é explorar as dinâmicas da comunidade e da escola por meio de ações e reflexões da realidade vivida, de forma que criem possibilidades de intervenções que gerem transformações (Guzzo\& cols., 2010) sociais e individuais a partir da e na escola.

Apesar do interesse que surge na comunidade escolar pela inclusão do psicólogo na instituição (Fundação Lemann, 2015), atualmente não existe obrigatoriedade de sua presença, a neste cenário de prática. As tentativas de mudanças partem de dois projetos de lei ${ }^{1}$, porém eles tramitam há mais de uma década entre a Câmara e Senado Federal sem definição. É importante considerar que a obrigatoriedade não garante uma práxis, ao contrário, pode até dificultar o cenário, já quea única garantia para uma atuação coerente e compromissada com todo o processo que envolve a comunidade escolar apenas consolida-se com/na formação e nas práticas compartilhadas.

A produção científica pode ser um importante meio de discussão e problematização do fazer do profissional em questão, bem como de divulgação da prática, do papel e da finalidade das atividades do psicólogo escolar e educacional. Diante disso, este artigo tem o objetivo de apresentar algumas das produções de PEE, publicadas de janeiro de 2000 a setembro de 2017, por meio de bases de indexação de revistas de produção científica que sejam de acesso livre e permitam a promoção da atuação de psicólogos na área. Buscou-se analisar, especificamente, como se dáatuação e as práticas desenvolvidas por psicólogo(s)/a(s) na área escolar e educacional.

\section{Método}

Para tanto, organizou-se a realização do levantamento da produção científica em três momentos: 1) constituição do corpus; 2) sistematização dos artigos selecionados; 3) análise do material. Todas as etapas feitas por três revisores, sob supervisão docente.

\section{1) Constituição do corpus}

No primeiro momento, objetivou-se incluir o maior número possível de artigos sobre o tema, pois os descritores poderiam ter sofrido variações no decorrer do período avaliado. Utilizou-se a combinação dos descritores: (psicologia) AND (escolar); (psicologia) AND (educação); (psicologia) AND (atuação); (psicologia) AND (práticas) e (psicologia) AND (atribuições). As bases de dados com interfaces online de busca de acesso livre verificadas foram: Scientific Eletronic Library Online (SciELO), por comportar parte signi-

\footnotetext{
1 Projeto de Lei n. 557/2013 que diz respeito à obrigatoriedade de disponibilização de atendimento psicológico ou psicopedagógico para estudantes e profissionais da educação, a estudantes e profissionais da educação das redes públicas de Educação Básica e o Projeto de Lei $n$. 3688/2000 que dispõe sobre a inclusão de assistentes sociais e psicólogos (as) nas escolas públicas. Disponível: https://www25. senado.leg.br/web/atividade/materias/-/materia/115921/pdf e ; http:// www.camara.gov.br/proposicoesWeb/fichadetramitacao?idProposic $\mathrm{ao}=20050$
} 
ficativa da produção científica brasileira em diferentes áreas do conhecimento; e o portal de Periódicos Eletrônicos de Psicologia (PePSIC), por indexar revistas mais específicas de psicologia.

Foram estabelecidos como critérios de inclusão: artigos completos, escritos em português, trabalhos de descrição ou análise/relato de práticas em PEE desenvolvidos em cenários brasileiros; e como critérios de exclusão: artigos de revisão, ensaios, capítulo de livros, artigos de discussão apenas teórica em PEE, ações de gestão e políticas públicas em educação, práticas derivadas de pesquisa científica, estágio, monitoria e pós-graduaçãono tema e aqueles realizados em serviços-escola de universidades e faculdades. Através da leitura dos títulos e resumos, aqueles trabalhos que preencheram os critérios em um primeiro momento foram incluídos. Os artigos repetidos foram retirados para o cômputo final. Na sequência, todos os artigos selecionados foram avaliados pelos revisores considerando a leitura e análise criteriosa do texto na íntegra.

Através da busca e da leitura de título e resumos foram identificados 174 artigos nas bases de dados utilizadas. Destes, foram excluídos por se tratarem de artigos de revisão 15, oito ensaios, 43 artigos de discussão apenas teórica em PEE, 27 ações de gestão e políticas públicas em educação e 75 de práticas derivadas de pesquisa científica, estágio, monitoria, trabalho de pós-graduação, aqueles realizados em serviços-escola de universidades. Restando um total de seis artigos de interesse a esta revisão.

\section{2) Sistematização dos artigos selecionados}

Para a exploração do corpus foi adotada a análise de conteúdo por meio da formação de categorias temáticas a partir da abordagem de Bardin (1977), somando-se a isso, a pré-análise, a exploração do material com o tratamento dos resultados e a interpretação. Diante disso, as categorias formadas foram: 1 - Ações desenvolvidas e 2 - Limites e perspectivas no desempenho das funções. Dentro destas categorias foram sistematizados três grupos conforme o lócus de atuação do psicólogo a) Escolas de nível infantil, fundamental e médio; b) Ensino superior; c) Organizações não-governamentais.

\section{3) Análise do material}

Através do corpus foi feita uma descrição geral segundo as categorias elaboradas. São descritos ainda os tipos de instituições educacionais locais, a região do país, profissional que desempenha e o ano de publicação.

\section{Resultados}

A atividade de análise dos seis artigos selecionados (tabela 1) permitiu observar que apenas um trata da atuação de psicólogo no ensino superior, quatrodizem respeito

Tabela 1. Artigos incluídos na revisão de periódicos científicos sobre as práticas e a atuação em Psicologia Escolar e Educacional entre 2000-2017. Brasil, 2017.

\begin{tabular}{|c|c|c|c|}
\hline & Autor & $\begin{array}{c}\text { Ano de } \\
\text { publicação }\end{array}$ & Título \\
\hline \multirow{4}{*}{$\begin{array}{l}\text { Ensino infantil, } \\
\text { fundamental e médio }\end{array}$} & Costa, A. S. \& Guzzo, R. S. L.; & 2006 & $\begin{array}{l}\text { Psicólogo Escolar e Educação Infantil: } \\
\text { um estudo de caso. }\end{array}$ \\
\hline & $\begin{array}{l}\text { Chagas, J. C., Pedroza, R. L. } \\
\text { S., \& Branco, A. U. }\end{array}$ & 2012 & $\begin{array}{l}\text { Direitos humanos e democracia } \\
\text { na educação infantil: atuação do } \\
\text { psicólogo escolar em uma associação } \\
\text { pró-educação. }\end{array}$ \\
\hline & $\begin{array}{c}\text { Chagas, J. C. \& Pedroza, R. } \\
\text { L. S. }\end{array}$ & 2013 & $\begin{array}{l}\text { Psicologia escolar e gestão } \\
\text { democrática: atuação em escolas } \\
\text { públicas de Educação infantil. }\end{array}$ \\
\hline & Vebber, F. C. & 2013 & $\begin{array}{l}\text { Psicologia Escolar: relato de uma } \\
\text { experiência no ensino fundamental. }\end{array}$ \\
\hline Ensino Superior & Caixeta, J. E. \& Sousa, M. A. & 2013 & $\begin{array}{l}\text { Psicologia Escolar na Educação } \\
\text { superior: atuação no Distrito Federal. }\end{array}$ \\
\hline $\begin{array}{l}\text { Organizações não } \\
\text { governamentais }\end{array}$ & Dadico, L. \& Souza, M. P. R. & 2010 & $\begin{array}{l}\text { Atuação do Psicólogo em } \\
\text { Organizações não Governamentais } \\
\text { na área de Educação. }\end{array}$ \\
\hline
\end{tabular}


às ações desenvolvidas em escolas de ensino infantil, fundamental e/ou médioe uma em organizaçãonão-governamental. A maior parte foi desenvolvida no Centro-Oeste e Sudeste do país, não havendo experiências no Nordeste ou Norte. Todos eles relatam experiências de profissionais que estiveram inseridos na instituição como psicólogos no momento da realização das atividades descritas. As produções são do intervalo de 2006 a 2014, no entanto a maior parte foi publicada em periódicos no ano 2013.

\section{1- Ações desenvolvidas}

Neste tópico, são descritas as ações desenvolvidas, lócus e elementos da atuação dos psicólogos nos espaços educacionais. Dos quatro trabalhos concernentes às práticas em escolas de ensino infantil, fundamental e médio, três dedicaram-se ao ensino infantil e uma ao ensino fundamental, e esta última inclui alunos do ensino médio na escola. As ações desenvolvidas em cada local diferenciaram-se não apenas pelo público, mas pela característica de cada local e tipo de atividade. Na creche em Campinas - SP, a psicóloga trabalha junto a 70 crianças entre três a dois anos e meio de idade, e apontacomopráticaspossíveisa esse público, o contato com os profissionais da escola e com os pais sobre as crianças; o acompanhamento do desenvolvimento da criança na escola; a escuta profissional da equipe pedagógica; a participação das atividades desenvolvidas na escola com as educadoras; o acompanhamento e orientação às estagiárias de psicologia na escola; o suporte ao educador nas rotinas da escola e o conhecimento do espaço físico, rotina e dos funcionários da escola (Costa \& Guzzo, 2006).

Afastando-se de uma gestão e de processos tradicionais a experiência da psicologia naAssociação Pró-Educação, em Brasília, parte de uma gestão compartilhada e associativa das responsabilidades e de decisão entre toda comunidade escolar. A coordenação é composta por psicólogo, coordenador pedagógico, diretoria e por grupos de pais e professores eleitos em assembleia geral. A psicóloga inserida nesse contexto apresentou, por meio de uma pesquisa participante de cunho etnográfico, a orientação para seu cotidiano e as relações possíveis, discorrendo no artigo como a lógica associativa implica à PEE possibilidades de desenvolvimento do papel de mediador das relações interpessoais, seja na construção da dimensão afetiva com a comunidade e a escola, ou na negociação cotidiana dos interesses pessoais, que fazem parte de espaços democráticos de forma que sua atuação, seja não de evitar conflitos, mas de aproveitá-los para desenvolver o grupo positivamente. Outro aspecto interessante da associação é a ausência de um documento formal instituído, comoo intitulado Projeto Político Pedagógico(PPP), a autora reconhece que em outras formas de produção (acadêmicas ou próprias da instituição) existe a possibilidade de orientação do grupo através deformações internas e também do recurso da transmissão da própria história constantemente, servindo a noção de identidade daquela comunidade, de seus valores e caminhos possíveis. Essa lógica compartilhada também era o mote das ações e dos espaços de socialização. Os processos de negociação partiam de uma intervenção pedagógica baseada na abordagem sociocultural construtivista do desenvolvimento com vistas a expor, partilhar, apreender e ressignificar as mensagens e os significados. Da mesma forma, eram "combinadas" as regras do cotidiano escolar, bem como a construção dos limites dos associados e profissionais (Chagas, Pedroza, \& Branco, 2012).

Já sob uma lógica democrática, profissionais da psicologia relataram sua experiência emescolas públicas de educação infantil do Plano Piloto do Distrito Federal. As ações desenvolvidas foram aelaboração e a reestruturação dos PPPs, atendimentos individuais e de grupo com as reuniões com pais de alunos, na formação dos professores nos processos de ensino e aprendizagem focada nas especificidades e ajustamento de cada necessidade e variabilidade de contexto, além de atuar na compreensão de como cada docente percebe sua prática democrática no coletivo e os significados dos conflitos cotidianos. Ainda houve a promoção da participação dos funcionários de formações, mediação de conflitos e na participação dos espaços democráticos, e por fim, junto às crianças coadunariam com a concepção da instituição de ensino, no caso, a escola adapta-se ao aluno e coloca-o como sujeito de desejos e direitos. Porém, ressalta-se que esse trabalho não consegue ser generalizado, ao contrário, existia por parte dos gestores e de alguns profissionais,que também atuavam como psicólogos, por um trabalho voltado ao atendimento individualizado a partir de diagnósticos dos desvios da normalidade e de rendimento escolar, ao invés de serem estas questões que poderiam ser aproveitadas para tornar o ensino mais plural (Chagas \& Pedroza, 2013). Não houve relato de trabalhos junto aos discentes nesse trabalho.

A experiência no ensino fundamental no serviço público de uma psicóloga do Rio Grande do Sul cita algumas atividades gerais em sua função, todavia, a descrição do trabalho refere-se com maior ênfase à implantação/implementação de um projeto intitulado "Direitos humanos nas séries iniciais", direcionado a alunos entre nove e 11 anos devido ao bullying e dificuldades de relacionamento interpessoais. O trabalho teve aporte teórico em Jean Piaget e Paulo Freire através da pedagogia nova e da educação problematizadora, respectivamente. E assim foram realizadas contação de história, pesquisa de conceitos, dinâmicas com imagens e o envolvimento da família de forma que fosse estimulada a dialogicidade no grupo para o enfrentamento dos conflitos. As ações acabaram envolvendo outros profissionais e elementos no seu decorrer, a saber, professores e motorista do ônibus escolar. O material e os recursos foram livros, quadrinhos, imagens e outros produzidos para temática dos direitos humanos ou que abarcassem o tema. E por fim, sintetiza que o fazer teve que ser (re)adequado às limitações institucionais, assim como as práticas possíveis a ela como profissional (Veber, 2013).

Sobre o nível superior, um único trabalho destinou-se ao desenvolvimento de intervenção institucional, este foi reali- 
zado em 2009, no qual,a partir de uma pesquisa-ação, à luz de práticas de ação-reflexão-ação,foi desenvolvido o Programa de Responsabilidade Social dentro de uma instituição de ensino superior privado localizada no Distrito Federal. O trabalho foi proposto e aplicado por três psicólogas com formação em PEE e pela dimensão institucional das práticas possíveis à área. As ações voltaram-se às políticas de ensino por meio da discussão dos projetos pedagógicos, com a intervenção pedagógica junto aos professores e auxilio as práticas de avaliação e aprendizagem e apoio psicopedagógico junto aos alunos; do Programa de Acompanhamento para o Trabalho e relacionamento com o mercado destinado no que tange os alunos nos seus estágios, além de promover a orientação e a formação por meio de programas de coaching e mentoring, com escuta e orientação vocacional; nas Políticas de Inclusão da faculdade, o serviço de psicologia ainda desenvolveu estratégias de adaptação e melhor atendimento aos alunos com deficiência e na realocação de alunos desempregados no mercado de trabalho; e apoio às atuações de responsabilidade social universitária tendo em vista o desenvolvimento de valores solidários e de sustentabilidade nos alunos (Caixeta \& Sousa, 2013).

A atuação de psicólogos em cinco organizações não-governamentais direcionadas a trabalhos na área de educação foram descritas por Dadico e Souza (2010) por meio de entrevistas. Os entrevistados desempenhavam diferentes funções (assistentes técnicos, pesquisadores, coordenadores de áreas ou de projetos específicos) e suas ações ocorriam em meio a equipes multidisciplinares ou postos abertos, de modo genérico aos profissionais da área de humanas. No entanto, em uma das ONGs, havia o desempenho específico da psicologia da educação com a realização de intervenção institucional, educacional ou terapêutica, principalmente, em oficinas educativas. Em algum momento nas instituições, todos os psicólogos aplicaram projetos que envolviam o desenvolvimento de novas tecnologias em educação, a realização de pesquisas, de atividades de arte e cultura, intervenção na escola, produção de eventos e a elaboração de materiais educativos de forma geral. Porém, a maior parte deles detinha no momento da entrevista a realização de funções que tinham a ver com seus pontos fortes, experiência, interesse e/ou habilidade.

\section{2 - Limites e perspectivas no desempenho das funções}

O contexto das comunidades com altos índices de violência e que têm condições sociais desfavoráveis refletem para a dinâmica escolar e para a psicologia a ideia decomo lidar com o medo, seja da comunidade ou dos gestores e professores em expor-se e denunciar quem infringe direitos e está envolvido com entes como o crime organizado e a polícia.Os limites de trabalho estão em sinergia com as dificuldades sociais.Desta forma, pensar em dinâmicas que visem à prevenção de agravamento à vida da criança é também propor-se a mudança social e política do país (Costa \& Guzzo, 2006).
Algumas outras dificuldades na prática psicológica dizem respeito à participação da comunidade escolar, principalmentepor parte dos funcionários que não querem ounão se envolvem nos espaços de tomada de decisão. Outra problemática surge pelo excesso de demandas dos serviços por práticas psicométricas, situação essa, agravada pelo desconhecimento dos gestores das possibilidades da atuação psicológica nas instituições. Os autores citam que a quantidade diminuta de psicólogos para a quantidade de escolas e a falta de estrutura reforçam a dificuldade da manutenção de atendimentos individualizados dos escolares e a lógica psicométrica para a identificação das necessidades (Chagas \& Pedroza, 2013).

As potencialidades dos modos de atuação não foi um elemento contido em todos os artigos, houve naqueles que o fizeram o foco na valorização dos processos. Principalmente, quando as experiênciasdestacavam como a superação da estrutura organizacional tradicional, por meio da lógica associativa, produz resultados positivos a toda comunidade escolar (Chagas, Pedroza, \& Branco, 2012). Por outro lado, quando o profissional encontra-se em instituição privada, existem contenções das práticas psicológicas quando o profissional é convocado apenas a aplicar ou implantar/implementar uma lógica já instituída, por exemplo, em instituições privadas de ensino superior já existe uma demanda bem clara ao psicólogo, e quaisquer outras questões devem corroborar com as necessidades do serviço (Caixeta \& Sousa, 2013).

No que se refereàs dificuldades do trabalho junto à proposta pedagógica Veber (2013), afirma que a execução de um projeto na escola é uma experiência que pode apontar carência da instituição por trazer elementos de entrave ao trabalho, como a dificuldade de ir além dos conteúdos formais já instituídos e da resistência à inclusão no currículo das relações do sujeito com ele mesmo, com o outro e com o meio sociocultural. E ressalta como a falta de mais experiências sendo compartilhadas na área de PEE é um empecilho à área.

Mesmo quando a instituição prediz certa liberdade e/ ou possibilita que suas potencialidades individuais e interesses sejam desenvolvidos, não significa a ausência de dificuldades, nas organizações não-governamentais, por exemplo, a realização de trabalhos burocráticos apareceu como um problema recorrente durante o desenvolvimento de projetos. Além do que, a falta de remuneração adequada a esses profissionais, o excesso de trabalho, o sentimento de cansaço e a não conciliação do trabalho com outras atividades profissionais e pessoais, como o estudo, seriam elementos constituintes das condições de trabalho na área. Um aspecto importante da fala dos psicólogos dessas organizações foi como o sentido social e político do trabalho desempenhado ededicado à educação brasileiraé um reforço positivo à prática do profissional (Dadico \& Souza, 2010).

\section{Discussão}

Apesar de a PEE ser considerada uma área clássica da Psicologia e ter considerável produção acadêmica (Ya- 
mamoto, Souza, \& Yamamoto, 1999; Paula, Sivieri-Pereira, 2015; Prezenszky, 2017), percebe-se que no período dos 17 anos pesquisados, foram poucos artigos que trataram de discutir a prática desenvolvida por profissionais inseridos nas instituições de ensino. Imagina-se que sob outros critérios de inclusão e exclusão, outros trabalhos pudessem ser incluídos nesta revisão. Porém, a parca quantidade de trabalhos de experiências desenvolvidas por profissionais em campo propicia algumas questões: os resultados ocorreram por uma questão metodológica? Ou foi uma questão de falta de sistematização dos dados pelos profissionais? Ou de ausência de experiências? Ou só há experiências na academia/universidade? Ou ainda, existe uma priorização por produções científicasem detrimento de relatos de experiência junto às revistas científicas? Ou as condições e/ou processo de trabalho não promovem o desenvolvimento de uma produção científica por parte dos trabalhadores? Essas e outras questões podem auxiliar a reflexão crítica na área da PEE. Todavia, cabe a outros trabalhos apontarem respostaspara estas.

Outro elemento importante é a concentração dos trabalhosem algumas regiões ou localidades. A produção científica pode, por diferentes fatores (ênfase curricular e orçamentária para pesquisas, limites na formação, concentração de instituição de ensino superior etc.), apresentar tal característica. No entanto, mesmo a ênfase em Psicologia Escolar sendo uma área que contribui significativamente para a consolidação da profissão em si, ela vem tendo pouco espaço na sociedade capitalista, a qual almeja, comumente, apenas formar profissionais de nível superior para atender ao mercado de trabalho, prova disto é como se espalham instituições voltadas às áreas de gestão e trabalho, saúde ou clínica por encaixarem-se melhor a esta possibilidade (Tizzei, 2014).

Outro elemento que pode ter auxiliado a não inclusão de algum trabalho a esta revisão, deve-se às próprias divergências teóricas e práticas da PEE que levam a uso de diferentes indexadores. O desacordo dá-se porque alguns pesquisadores e profissionais impulsionarem a ideia de que falta com o que a psicologia dar contribuição aos problemas do sistema educacional brasileiro, não devendo ser este o cenário deste profissional. Com uma ideia de interface há aqueles que apoiam aconcretização da inserção do psicólogo por meio de atuação junto à pedagogia: os psicopedagogos. Porém, essa aproximação historicamente faz parte da tentativa de fugir do estereótipo das práticas psicométricas (Maluf,1999). No outro extremo, surgem as propostas como as de Martinez (2010) e Guzzo e cols.(2010) e outros que apoiam a discussão do papeldo psicólogo escolar visando o compromisso social, político e ético desse profissionalcom a educação brasileira e com o desenvolvimento da comunidade escolar. Essa ideia consegue unir a necessidade de uma formação e uma prática crítica com a realidade das comunidades numa intersecção mais coerente à atuação do profissional de psicologia no âmbito de qualquer instituição de ensino.

Diante disso, cabe comentar como a atuação no Ensino Infantil, Fundamental e Médio, aqui apresentada, trouxe elementos que corroboram com a necessidade de implicar-se com os contextos sociais, haja vista sua importância no desenvolvimento da criança de acordo com sua realidade. Entretanto, também apresentou como o profissional precisa discernir até onde corrobora, ou não, com dinâmicas cristalizadas ou mesmo solicitadas das instituições e organizações em que estão inseridos. O compromisso com a educação brasileira deve ser um movimento individual do profissional (Guzzo \& cols., 2010; Guzzo, Mezzalira, \& Moreira, 2012) que colabore e não reforce práticas sistemáticas individualizantes. Ou seja, novamente, essa posição tem muito a ver com o tipo de formação e de experiências acadêmicas e extra-acadêmicas, além das preferências individuais, afinal, independente das ênfases curriculares, seja em PEE ou não, a reflexão crítica na formação de graduaçãoimpulsiona essa coerência com as demandas sociais.

É uma preocupação a ênfase dada àlógicas psicométricas clássicas que servem à epistême, que por sua vez, servem à medicalização e medicamentalização de modos de vida e de consumo, tendo em vista que ela pode contribuir para a categorização, bem como com a patologização dos alunos. São importantes os impactos desse tipo de categorização nos indivíduos, na produção subjetiva com a realidade, nas relações constituídas e nas identidades sociais, além de ser um pressuposto que ignora que todo ser humano está incluso historicamente e culturalmente dentro de um contexto e que por apropriações das objetivações produzidas pela humanidade (instrumentos e signos) ele modifica suas condições de vida e também se transforma. Ou seja, fica impossível analisar o indivíduo desconsiderando a totalidade concreta que perfaz o homem em determinado contexto e momento (Eidt \& Tuleski, 2007).

A literatura, assim como aqui verificado, corrobora com a ideia de escassez de práticas da atuação nas instituições de ensino superior (Bisinoto \& Marinho-Araújo, 2011; Pandita-Pereira \& Sekkel, 2012), bem como em outros níveis de ensino e em diferentes localidades. As possibilidades de ação são inúmeras, mas apesar disso, demandam-se aos profissionais práticas individuais e coletivas que inviabilizam outras possibilidades no ensino superior (Bisinoto \& Marinho-Araújo, 2011; Santana, Pereira, \& Rodrigues, 2014; Marinho-Araújo \& Neves, 2016) e no ensino profissionalizante (Pandita-Pereira \& Sekkel, 2012; Prediger \& Silva, 2014). Apesar de acreditar que as unidades educacionais públicas poderiam ser espaços com maior abertura ás possibilidades do que uma instituição privada (Caixeta \& Sousa, 2013), o que se percebe é que a área de PEE ainda tem desafios não só na sua inserção nos diferentes espaços, mas também da atuação possível, seja no serviço público ou privado.

As possibilidades de inserção em locais e espaços educacionais estão aquém das potencialidades que a PEE pode desenvolver. Entende-se que a não obrigatoriedade aliada à falta de compreensão das possibilidades de atuação, além o próprio cenário atual da educação brasileira, favorecem essa dificuldade. A ausência de regulamentação da prestação de serviços da psicologia junto as unidade de 
ensino do país continua a levar a fragilidade á área. Mesmo que sejam garantidas a presença do profissional, a reflexão sobre o papel, a função e a finalidade junto às políticas educacionais do país (ou a crítica a estas), necessitar-se-ia mais para assim ir além do que se espera da psicopedagogia, da psicoterapia e da realização de avaliação psicológica.

Esta revisão visou identificar e descrever quais eram as práticas/ações desenvolvidas; verificou-se que elas focaram-se, especialmente, em atividades junto ao aluno no que diz respeito ao desenvolvimento e a aprendizagem demonstrando a ausência de ações no âmbito institucional e uma diminuta quantidade de ações que envolvessem a comunidade escolar (pais, professores e alunos) de forma participativa e coerente com os territórios.Essa indicação parte dos trabalhos selecionados, no entanto,são possíveis outras análises e percepções. Observamos que a partir de outra sistemática de análise da literatura, outras possibilidades são apresentadas de atuação da PEE, por exemplo, Guzzo e cols. (2010) verificaram como ações exequíveis àquelasvoltadas à problemática das necessidades especiais, a formação do educador e a orientação profissional, com o uso principalmente das abordagens histórico-cultural e cognitiva, direcionadascom maior ênfase a grupos do ensino superior e fundamental.

Diante do que foi discutido até o momento, nota-se certo distanciamento entre o que é teorizado e a prática na PEE. Essa situação pode decorrer do que Coll (2004) afirmava ser o fato de que as tentativas de inovação e de melhoria das práticas escolares nem sempre incorporam osavanços e os progressos da pesquisa e da teoria produzida. Para tal, à psicologia, poderia caber o que Corte (conforme citado por Coll, 2004) aponta como três critérios diminuidores da distância entre teoria e inovação na prática: I) adoção de um enfoque holístico do ambiente da aprendizagem, seja no que concerne ao aluno e professores, mas também ao contexto; II) assegurar uma boa comunicação recíproca sob um formato acessível, aceitável e utilizável pelos professores na transmissão dos objetivos, resultados e enfoques; III) indução da mudança de valores e crenças dos professores a despeito das finalidades da educação escolar, do ensino eficaz e da aprendizagem significativa.

Um limite que também se torna uma possibilidade sãoas atuações nos mais diferentes contextos de ensino, para além da instituição pública, afinal são contextos diferenciados e permitir-se olhar os aspectos socioculturais, históricos, relacionais que vão além de aplicar teorias descontextualizadas, pode ajudar no desenvolvimento da PEE com potencialidade de mudança social. Vejamos a riqueza de possibilidade na experiência de Chagas, Pedroza e Branco (2012) na Associação Pró-Educaçãoà base de conceitos e práticas democráticas e de mobilização da comunidade.

As dificuldades são inúmeras, pois são desafios desse espaço de tensão que se dá dessa celeuma de encontros. Porém, a estrutura, ou a falta dela, bem como as condições e o processo de trabalho perfazem a história do trabalhador no mundo moderno, sendo que a superação ou a melhor convivência possível desses elementos da rotina também dizem respeito à posição deste profissional com a ética e com o compromisso social, com a escola e com a vida, o modus operandi é um reflexo dessa complexidade. Desta forma, a formação poder contribuir enormemente com as reflexões e as posições possíveis do sujeito no mundo.

\section{Considerações Finais}

Por fim, tendo em vista a articulação histórica da educação com a psicologia ressalta-se para o momento atual o esforço em reconhecer o compromisso social da escola e das políticas educacionais. Ao psicólogo é imprescindível afastar-se da individualização dos alunos, por ser esta uma prática apoiada em conceitos que segregam e são descontextualizados do processo do desenvolvimento e o que lhe permeia. Assim, reforçamos a necessidade de aproximação com as discussões de papel social e político do profissional com a educação que pode despontar desde sua formação, até o exercício profissional, seja militando (Dadico \& Souza, 2010) ou colocando quais suas motivações pessoais e profissionais (Guzzo \& cols., 2010). Dessa forma, acreditamos que esse trabalho possa contribuir com a síntese de experiências a uma área de grande potencialidade e de difícil articulação face atodos os envolvidos e os contextos. No entanto, desponta como área prática e de militância da Psicologia que não pode perder campo, atuação e inovação.

\section{Referências}

Bardin, L. (1977). Análise de conteúdo. (Reto, L. A. \& Pinheiro, A.,Trad.). Lisboa: Edições 70.

Barbosa, D. R. (2011). Estudos para uma história da Psicologia Educacional e Escolar no Brasil. Tese de Doutorado. Instituto de Psicologia, Universidade de São Paulo, São Paulo - SP. Disponível: www.teses.usp.br/teses/disponiveis/47/47131/tde22072011-163136/pt-br.php

Bisinoto, C.; Marinho-Araújo, C.M. (2011). Psicologia escolar na educação superior: atuação no Distrito Federal. Psicologia em Estudo,16(1), 111-122. Recuperado: 15 nov. 2018. Disponível: www.scielo.br/pdf/pe/v16n1/a13v16n1.pdf

Caixeta, J. E.; Sousa, M.A. (2013). Responsabilidade social na educação superior: contribuições da psicologia escolar. Psicologia Escolar e Educacional, 17(1), 133-140. Doi: http://dx.doi. org/10.1590/S1413-85572013000100004

Projeto de lei 3688/2000. Dispõe sobre a introdução de assistente social no quadro de profissionais de educação em cada escola. Recuperado: 15 nov. 2018. Disponível: http://www.camara.gov.br/ proposicoesWeb/fichadetramitacao?idProposicao $=20050$

Chagas, J. C.; Pedroza, R. L. S. (2013). Psicologia escolar e gestão democrática: atuação em escolas públicas de Educação Infantil. 
Psicologia Escolar e Educacional, 17(1), 35-43.

Chagas, J. R. A.; Pedroza, R. L. S.; Branco, A. U. (2012). Direitos humanos e democracia na educação infantil: atuação do psicólogo escolar em uma associação pró-educação. Estudos de Psicologia, 17(1), 73-81. Doi: http://dx.doi.org/10.1590/S1413294X2012000100009

Coll, C. (2004). Concepções e Tendências Atuais em Psicologia da Educação. In: Coll, C.; Marchesi, A.; Palacios, J. (Org.), Desenvolvimento Psicológico e Educação. Psicologia da Educação Escolar (Vol. II, $2^{\text {a }}$ ed.). Porto Alegre: Artmed.

Costa,A.S.;Guzzo, R.S.L. (2006). Psicólogoescolare educação infantil: um estudo de caso. Revista Escritos Sobre Educação, 5(1), 05-12. Recuperado: 15 nov. 2018. Disponível: http://pepsic.bvsalud.org/ scielo.php?script=sci_arttext\&pid=\$1677-98432006000100002

Dadico, L.; Souza, M. P. R. (2010). Atuação do psicólogo em organizações não governamentais na área da Educação. Psicologia: Ciência e Profissão, 30(1),114-131. Recuperado: 15 nov. 2018. Disponível: http://pepsic.bvsalud.org/scielo. php?script=sci_arttext\&pid=S1414-98932010000100009

Eidet, N. M.; Tuleski, S. C. (2007). Discutindo a medicalização brutal em uma sociedade hiperativa. In: Meira, M. E. M.; Facci, M. G. D. (Orgs.), Psicologia histórico-cultural: contribuições para o encontro entre a subjetividade e a educação(pp. 221-243). São Paulo: Casa do Psicológo.

Fundação Lemann (2015). Conselho de Classe. 2015. A vida dos professores sobre a educação no Brasil. São Paulo: Fundação Lemann. Recuperado: 15 nov. 2018. Disponível: https:// fundacaolemann.org.br/storage/materials/8Apd1Gn7RxiYqAJWKy rl6WFpfN4iFYimYx1v90VI.pdf

Guzzo, R. S. L.; Mezzalira, A. S. C.; Moreira, A. P. G. (2012). Psicólogo na rede pública de educação: embates dentro e fora da própria profissão. Psicologia Escolar e Educacional, 16(2), 329-338.

Guzzo, R. S. L.; Mezzalira, A. S. C.; Moreira, A. P. G.; Tizzei, R. P.; Silva-Neto, W. M. F. (2010). Psicologia e Educação no Brasil: Uma Visão da História e Possibilidades nessa Relação. Psicologia: Teoria e Pesquisa, 26 (especial), 131-141. http://dx.doi. org/10.1590/S0102-37722010000500012

Machado, A. M. (2003). Os psicólogos trabalhando com a escola: intervenção a serviço do quê? In: Meira, M. E. M.; Antunes, M. A. M. (Orgs.), Psicologia escolar: práticas críticas (pp. 63-86). São Paulo: Casa do Psicólogo. Recuperado: 15 nov. 2018. Disponível: www.pepsic.bvsalud.org/scielo.php?script=sci_arttext\&pid =S1414-69752014000200011

Maluf, M. R. (1999) Novos Rumos para a Psicologia e os Psicólogos da Educação. Psicologia da Educação. Revista do Programa de Estudos Pós-Graduados PUC/SP, 9, 15-41.
Marinho-Araújo, C. M.; Neves, M. M. B. J. (2016). Psicologia Escolar e a formação continuada em serviço: encurtando distâncias entre teorias e práticas. Boletim Academia Paulista de Psicologia, 1(07), 56-71. Recuperado: 15 nov. 2018. Disponível: www.scielo.br/ scielo.php?script=sci_arttext\&pid=S0103-166X2016000200199

Martínez, A. M. (2010). O que pode fazer o psicólogo na escola? Em aberto, 23(83), 39-56. Recuperado: 15 nov. 2018. Disponível: www.repositorio.unb.br/handle/10482/6292

Moreira, A. P. G.; Guzzo, R. S. L. (2014). O psicólogo na escola: um trabalho invisível?. Gerais: Revista Interinstitucional de Psicologia, 7(1), 42-52. Recuperado: 15 nov. 2018. Disponível: www.soa. fafich.ufmg.br/gerais/index.php/gerais/article/viewFile/335/322

Pandita-Pereira, A.; Sekkel, M. C. (2012). Possibilidade de atuação para o licenciado em Psicologia na Etecs. Psicologia: Ciência e Profissão, 32(4), 972-985. Recuperado: 15 nov. 2018. Disponível: $\quad$ www.scielo.br/scielo.php?script=sci_arttext\&pid $=$ S1414-98932012000400015

Pasqualini, M. G.; Souza, M. P. R.; Lima, C. P. (2013). Atuação do psicólogo escolar na perspectiva de proposições legislativas. Psicologia Escolar e Educacional, 17(1), 15-24. Recuperado: 15 nov. 2018. Disponível: www.scielo.br/scielo.php?script=sci_arttex t\&pid=S1413-85572013000100002

Paula, E. L. P. de \& Sivieri-Pereira, H. de O. (2015). Psicologia Escolar e Educacional: um levantamento bibliográfico entre os aos 2008 e 2012. Psicologia Escolar e Educacional, 19(13), 455-462. Doi: http://dx.doi.org/10.1590/2175-3539/2015/0193860

Prediger, J.; Silva, R. A. N. (2014). Contribuições à prática do Psicólogo na Educação Profissional. Psicologia: Ciência e Profissão, 34(4), 931-939. Recuperado: 15 nov. 2018. Disponível: www.scielo.br/ pdf/pee/v18n2/1413-8557-pee-18-02-0229.pdf

Prezenszky, B. C. (2017). Coerência interna em pesquisas em Psicologia e contribuições à Educação: análise da produção no periódico Psicologia Escolar e Educacional. Dissertação de Mestrado, Universidade Federal de São Carlos, São Carlos - SP. Recuperado: 15 nov. 2018. Disponível: https://repositorio.ufscar. $\mathrm{br} /$ handle/ufscar/9176?show=full

Projeto de Lei do Senado n. 557, de 2013. Dispõe sobre o atendimento psicológico ou psicopedagógico para estudantes e profissionais da educação. Autoria Comissão de Direitos Humanos e Legislação Participativa. Recuperado: 15 nov. 2018. Disponível: https://www25. senado.leg.br/web/atividade/materias/-/materia/115921/pdf

Santana, A. C.; Pereira, A. B. M.; Rodrigues, L. G. (2014). Psicologia Escolar e educação superior: possibilidades de atuação profissional. Psicologia Escolar e Educacional, v. 18, n. 2, pp. 229237.

Souza, M. P. R.; Ramos, C. J. M.; Lima, C. P.; Barbosa, D. R.; Calado, V. A.; Yamamoto, K. (2014). Atuação do psicólogo 
na educação: análise de publicações científicas brasileiras. Psicologia da Educação, 38(1), 123-138. Recuperado: 15 nov. 2018. Disponível: https://revistas.pucsp.br/index.php/psicoeduca/ article/view/22808/19409

Tizzie, R. P. (2014). Formação em Psicologia Escolar: Perspectiva crítica na ênfase para o campo educativo. Tese de doutorado, PUC Campinas, Campinas - SP. Disponível: www.tede.bibliotecadigital. puc-campinas.edu.br:8080/.../Raquel\%20Pondian\%20Tizzei.pdf
Veber, F. C. (2013). Psicologia escolar: um relato de uma experiência no ensino fundamental. Revista Psicologia: Teoria e Prática,15(1), 194-207. Recuperado: 15 nov. 2018. Disponível: http://pepsic. bvsalud.org/pdf/ptp/v15n1/15.pdf

Yamamoto, O.H.; Souza, C.C.; Yamamoto, M.E. (1999). A produção científica na psicologia: uma análise dos periódicos brasileiros de 1990 - 1997. Psicologia, Reflexão e Crítica, 12, 549- 565. Recuperado: 15 nov. 2018. Disponível: www.scielo.br/scielo. php?script=sci_arttext\&pid=S0102-79721999000200019

Recebido: 26 de dezembro de 2017

Aceito: 09 de maio de 2018 unrestricted use, distribution and reproduction in any medium, provided the original article is properly cited. 